\title{
Critical values of mechanical stress and strain during traumatic cervical spinal cord injury: Clinical study with the use of Finite Element Modelling
}

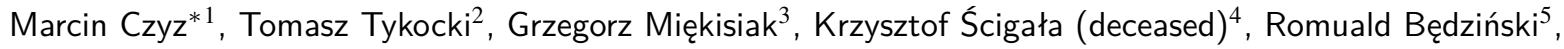 \\ Włodzimierz Jarmundowicz ${ }^{6}$ \\ ${ }^{1}$ Department of Spinal Surgery, The Royal Orthopaedic Hospital NHS Trust, UK \\ ${ }^{2}$ Institute of Psychiatry and Neurology, Department of Neurosurgery, Warsaw, Poland \\ ${ }^{3}$ Department of Neurosurgery, Regional Medical Center, Polanica Zdroj, Poland \\ ${ }^{4}$ Division of Biomedical Engineering and Experimental Mechanics, Wroclaw University of Technology, Poland \\ ${ }^{5}$ Division of Biomechanics, University of Zielona Gora, Poland \\ ${ }^{6}$ Department of Neurosurgery, Wrocław Medical University, Poland
}

Received: August 16, 2016

DOI: $10.5430 / j b g c . v 6 n 2 p 22$
Accepted: September 4, $2016 \quad$ Online Published: September 12, 2016

URL: http://dx.doi.org/10.5430/jbgc.v6n2p22

\begin{abstract}
Study design: Prospective case-control study.

Objective: Aim of the study was to assess critical values of mechanical stress and strain in the cervical spinal cord based on the Finite Element Method (FEM) simulations of specified clinical cases.

Summary of background data: The knowledge about the values and distribution of tension and deformation, which are noted at the moment of traumatic spinal cord injury (tSCI) may enable determination of the range of primary and secondary injury. Methods: Total of 28 patients after cervical spine (C-spine) injury were enrolled, 14 with neurological symptoms of tSCI (study group, SG) and 14 neurologically intact (control group, CG). Both groups were age and sex matched. A three-dimensional (3D) numerical model of the cervical spinal cord containing dura and pia matter together with denticulate ligament was created. The variable boundary conditions were established individually for each case and allowed to reconstruct the moment of the injury in computer environment. Factors differentiating between SG and CG were tested with multiple logistic regression model. The predictors of ASIA scale outcomes were evaluated in the ordinal multinomial probit regression model.

Results: There were no correlations between age, sex and the level of injury and the values of stress and strain. The results in longitudinal axis (z), in stress (OR-6.3; 95\%CI 3.94-8.78; $p<.033$ ) and strain (OR-7.8; 95\%CI 3.03-10.19; $p<.046)$ were the risk factors of neurological deficits after tSCI. The cut off value for stress was $8.1 \mathrm{kPa}$ (sensitivity-85.7\%; specificity-78.6\%; AUC-0.819, $p<.001$ ), and for strain 0.0117 (sensitivity-92.9\%; specificity-72.5\%; AUC-0.645, $p<.001$ ). Results in the longitudinal axis (z), in stress and strain correspond with grading in ASIA scale. One grade change in ASIA scale correlates with the decrease in $\mathrm{z}$ axis by $4.01 \mathrm{kPa}$ and 0.012 in stress and strain respectively.

Conclusions: The severity of damage of osseous and ligament structures of the spine, significantly influences the range of the mechanical stress applied to the spinal cord. Neural tissue of the spinal cord is the most resistant to the mechanical stimulus acting in sagittal direction, distraction appears to be the most destructive component of the injury phenomenon.
\end{abstract}

Key Words: Finite Element Analysis, Spinal cord injury, Biomechanics, Neuroimaging

${ }^{*}$ Correspondence: Marcin Czyz; Email: marcin.czyz@nhs.net; Address: The Royal Orthopaedic Hospital NHS Trust, Bristol Rd S, B31 2AP, Birmingham, UK. 


\section{INTRODUCTION}

The traumatic spinal cord injury (tSCI) occurs as a result of a mechanical stimulus applied to the fragile neural tissue. ${ }^{[1-4]}$ The load applied to the spinal cord at the moment of injury is most often the derivative of forces, which lead to a rapid contact between bony elements or fragments of the intervertebral disc and the spinal cord.

Based on the results reported by Maikos et al..$^{[5]}$ it may be concluded that the knowledge about the values and distributions of stress and deformation, which are noted at the moment of SCI, may enable determination of the range of primary and secondary injury. ${ }^{[6,7]}$ This would possibly allow the precise and reliable predicting of actual extent of tSCI and remote neurological after-effects of the secondary injury. ${ }^{[8,9]}$

Due to the significant progress in the field of IT sciences, it is currently possible to visualise and analyse the phenomena accompanying the tSCI in the environment of computer applications. The most popular tool used for this purpose is the Finite Element Method (FEM). The FEM enables to conduct the studies on objects' strength, deformation, tension, displacement, heat transfer and liquid transfer simulation performed in computer mechanics. The subjects of interest in the study may also be dynamics, kinematics and statics of physical systems, electrostatic, magnetostatic and electromagnetic interactions. ${ }^{[10-15]}$ Its usefulness in the analysis of clinical tSCI cases was documented previously. ${ }^{[16-18]}$ Numerous studies on the distribution of spinal cord deformations at the moment of injury were conducted in the past. ${ }^{[3,5,19-22]}$ According to our knowledge there was no clinical study describing critical values of mechanical stress and strain for the cervical spinal cord performed previously.

Aim of the study was to assess the ranges of relatively safe and critical values of mechanical stress and strain in particular zones of the spinal cord cross-section based on FEM simulations and strength analyses of specified clinical cases.

\section{MATERIAL AND MethodS}

The study has been approved by the Local Ethics Committee, each patient signed a written consent. 28 patients subjected injury to the cervical spine (C-spine) comprised the clinical material. This group included 14 patients with neurological symptoms of tSCI after high velocity cervical spine injury [road traffic accidents, falls from a high and diving] (study group, SG) and 14 patients without symptoms of spinal cord injury (control group, CG).

Inclusion criteria: Age from 16 to 65 years; High velocity injury to the cervical spine excluding penetrating injuries $(e . g$. gunshot); The time between the injury and admission no

Published by Sciedu Press longer than 12 hours; Lack of symptoms of severe systemic disease (e.g. sepsis, infection with HIV/HBV/HCV virus, neoplasmatic disease, diabetes, multiple sclerosis); Lack of previous injuries in the central and peripheral nervous system which may disturb an assessment of the neurological state of the patient.

The classification of the mechanism of spine injury was conducted according to recommendations developed by AOSpine group dividing subaxial injuries to the cervical spine depending on the mechanism and morphology. ${ }^{[23,24]}$ As per AOSpine classification stable compressive fractures, related predominantly to the axial load, were assigned the letter A; fractures with the involvement of the posterior column, related mostly to the hyperflexion or hyperextension letter B, injuries with the component of translation/rotation letter C. An assessment of the range of injury of osseous and ligament structures was additionally introduced based on a twenty-point Moore's scale also known as Cervical Spine Injury Severity Score. ${ }^{[25]}$ This scale introduced in 2006 is based on summations of analog scores quantifying amount of injury-related dislocation to each of four spinal columns (anterior, posterior and two lateral pillars). The injury to each of four columns can be scored as high as 5 and the severity of the injury can be thus expressed as a number within a range $0-20$. The radiological analysis was conducted based on the CT scans performed following the axial helical protocol with a $0.625 \mathrm{~mm}$ slice thickness and a gantry tilt of zero degrees using a spiral Dual HiSpeed (GE Healthcare) CT scanner. The MR imaging was performed on the GE 1.5T Signa HDx scanner with using an eight-channel sending-receiving coil dedicated for the cervical spine. The scans were obtained in sagittal and axial planes, following sequences were performed: T1 SE, T2 frFSE, T2 + FASAT.

Detailed neurological examinations of each patient were performed on admission by a Board Certified neurologist blinded to the results of the imaging. The questionnaire of the ASIA scale of the American Association of Spine Injuries was filled in every case. ASIA score summarises minimal elements of neurologic assessment for all patients with a spinal injury. These minimal elements are strength assessment of ten muscles on each side of the body and pin-prick discrimination assessment at 28 specific sensory locations on each side.

These minimal elements are strength assessment of ten muscles on each side of the body and pin-prick discrimination assessment at 28 specific sensory locations on each side. A maximum possible score is 112 points for pin prick and light touch sensation for a patient with normal sensation. The sum of all 20 muscle yields a total motor score with a maximum 
possible score of 100 points for patients with no weakness. A different score, however for upper limbs and lower limbs can be calculated making it 50 maximum for both upper and lower limb. Voluntary anal contraction is also noted. The ASIA impairment scale describes a person's functional impairment as a result of their spinal cord injury. ASIA A Complete spinal cord injury: no motor or sensory function in the lowest sacral segment (S4-S5); B - Incomplete: sensory function below neurologic level and in S4-S5, no motor function below neurologic level; C - Incomplete: motor function is preserved below neurologic level and more than half of the key muscle groups below neurologic level have a muscle grade less than 3; D - Incomplete: motor function is preserved below neurologic level and at least half of the key muscle groups below neurologic level have a muscle grade
$>3$; E - Normal: sensory and motor function is normal. ${ }^{[26,27]}$ The assessment was accomplished with deep sensation testing not included in to the ASIA scale.

\subsection{Numerical model}

The detailed description of the FEM model geometry, discretisation and validation as well as study design was presented previously. ${ }^{[18,28]}$ Briefly, a three-dimensional (3D) numerical model of the spinal cord white and grey matter in a cervical segment accomplished with dura and pia matter together with denticulate ligament was elaborated using the ANSYS Multiphysics 12.1 (ANSYS, Inc. USA) software. The strength parameters of white and grey matter, dura and pia mater as well as denticulate ligament were established based on the available literature. ${ }^{[19,29-32]}$ The illustration of the model is presented in Figure 1.
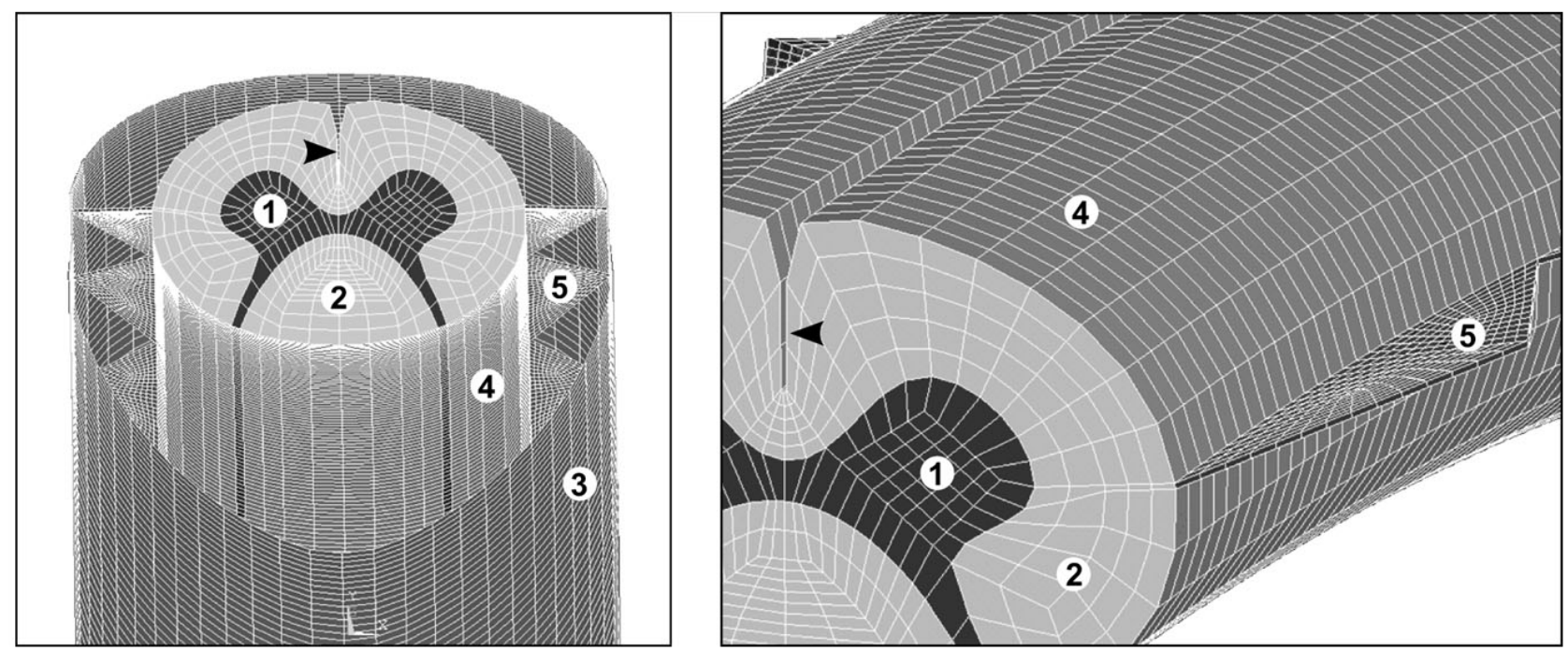

Figure 1. Finite element model of the human cervical spinal cord

Left side - general look with axial section. Right side - oblique projection of the model without dural sac. Note the composite structure of the denticulate ligament. Grey (1) and white matter (2), dural sac (3), pia matter (4) and denticulate ligament (5) are visible. Black arrow indicates anterior median fissure.

In order to establish the usefulness of the model for clinical tests and verification of theoretical assumptions accepted during its elaboration, it was subjected to experimental validation. ${ }^{[28]} \mathrm{A}$ fresh porcine cervical spinal cord specimen was divided into seven anatomical segments. Each of the seven segments underwent a gradual, controlled dorso-ventral compression with $0.5 \mathrm{~mm}$ intervals. The amount of displacement noted in the reference points of the specimen's cross-section was documented. Values obtained in-vitro were compared to the results of the simulated compression of the FEM model of the spinal cord, created based on the authorial protocol. There were no statistically significant differences in the trajectories of the control points between the experimental and numerical models noted.

\subsection{Simulation of the injury}

The model was initially fixed of proximal and distal ends in horizontal (X), sagittal (Y) and longitudinal (Z) axis. The variable boundary conditions were established individually for each clinical case and allowed to reconstruct the moment of injury in the computer environment. ${ }^{[18,28]}$ At first stage the displacement applied to a specified site of the spinal cord model - its direction, value and point of application were determined individually for each clinical case based on a metrological analysis of CT and MRI images, whose results were registered in the form of individualized Injury Cards. 
For every case the size of the spinal canal, spinal cord and subarachnoid space were established. The shape and size of the bony/soft tissue fragment injuring the spinal cord was established and relevant data was used while designing the injury simulation. While simulating moment of the injury the dura of the individualized FEM model was impacted with an indefinitely high speed by bony or soft tissue fragment of the shape estimated based on the imaging studies and parameters obtained from the literature available. The load of the impact was transferred on the spinal cord via dura and pia mater. This methodology is accepted as an effective one and is used in many such cases. ${ }^{[16,17]}$ Based on the results of the study of Hall et al..$^{[1]}$ which proved that the average amount of the spinal canal occlusion occurring during the high velocity spinal injury reaches $80 \%$ of its sagittal diameter it was accepted that in the study group, the maximum occlusion of the spinal canal reached this extent. In the CG the maximum accepted value of spinal canal stenosis at the moment of injury was that which was observed in the imaging studies conducted over the admission presuming fairly stable nature of the fracture/dislocation noted. While one of the aspects of the spinal cord was being injured the opposite one was fixed. It simulated the presence of the osseous framing of the spinal canal.

\subsection{Computational procedure}

The final reconstruction of the moment of tSCI involved solving a range of linear equations describing the state of pressure and deformation of particular three-dimensional nodes of the FEM model mesh. The calculations were performed by XW 8600 (Hewlett-Packard, USA) computational station equipped with two four-core Intel Xeon X5470 3.33 processors, 32Gb RAM, and disc RAID matrices.

\subsection{Elaboration of results}

Within the post-processing stage the results of the calculations were brought to a form enabling further analysis. The following were elaborated:

(1) A 3D model of the injured segment of the spinal cord deformation at the moment of maximum occlusion of the spinal canal by the osseous fraction.

(2) Sagittal sections of the model of the cervical fragment of the spinal cord with a visualisation of the distribution of areas of tension and deformation in the following axes: lateral, anterior-posterior and cephalo-caudal at the site of injury.

(3) Axial sections of the model of the cervical fragment of the spinal cord at the level of the site of injury with a visualisation of the distribution of tension areas and deformation in the following axes: $\mathrm{X}, \mathrm{Y}$ and $\mathrm{Z}$ at the site of injury.
Based on the obtained images, the maximum values and distributions of components of the tension and deformations state for injured segments of the spinal cord were established. The following anatomical-functional areas of the spinal cord section were established due to their significance from a clinical point of view (see Table 1).

Table 1. Anatomical-functional areas of the spinal cord section

\begin{tabular}{|c|c|}
\hline No. & Areas of the spinal cord section \\
\hline 1 & $\begin{array}{l}\text { The anterior column (anterior spino-thalamic tract) - } \\
\text { transduction of tactile stimuli }\end{array}$ \\
\hline 2 & $\begin{array}{l}\text { The abdominal part of the lateral columns (lateral } \\
\text { spino-thalamic tract) - transduction of pain stimuli }\end{array}$ \\
\hline 3 & $\begin{array}{l}\text { Posterior columns (bundles: wedged and gracile) - } \\
\text { bathyaesthesia transduction }\end{array}$ \\
\hline 4 & $\begin{array}{l}\text { The medial part of anterior column (corticospinal } \\
\text { anterior tract) - transduction of stimuli responsible for } \\
\text { studied movements }\end{array}$ \\
\hline 5 & $\begin{array}{l}\text { The reticulospinal tract - responsible for automatic } \\
\text { activity of respiratory muscles }\end{array}$ \\
\hline 6 & $\begin{array}{l}\text { The Medial part of the lateral columns (corticospinal } \\
\text { lateral - pyramidal tract) - transduction of stimuli } \\
\text { responsible for studied movements }\end{array}$ \\
\hline 7 & $\begin{array}{l}\text { Frontal horns of grey matter - movements of muscles } \\
\text { assorted by a given segment of the spinal cord }\end{array}$ \\
\hline 8 & $\begin{array}{l}\text { The internal part of a spinal cord section localised around } \\
\text { the central canal }\end{array}$ \\
\hline
\end{tabular}

\subsection{Statistical analysis}

SPSS 21.0 (SPSS, Chicago, Illinois, USA) and MedCalc 12 (MedCalc Software bvba) were used for the statistical analysis of the results obtained. The significance level was established as $p<.05$. A non-parametric Spearman's rank correlation was used to assess relations between the severity of the cervical spine injury by means of AOSpine and Moore's scores and results of the FEM simulations. Factors differentiating between SG and CG were tested with multiple logistic regression model. The predictors of ASIA scale outcomes were evaluated in the ordinal multinomial probit regression model.

\section{Results}

Total of 28 patients ( 3 women and 25 men) met inclusion criteria. The mean age of the patients was $35 \pm 14$ years. In $14(50 \%)$ of cases, no neurological symptoms of SCI were observed on examination (ASIA E - CG). Basic epidemiological and demographical data and the degree of spine and SCI severity according to the AO and Moore's scale are presented in Table 2. There were no significant differences in terms of age ( $t$-Student $p=.71$ ) and sex (Fisher's $p=1.0$ ) noted between $\mathrm{SG}$ and $\mathrm{CG}$. 
In $4(14 \%)$ cases complete (ASIA A) and in 10 further (35.7\%) incomplete SCI (5 - ASIA B; 1 - ASIA C and 4 - ASIA D) were noted. There was no linear correlation between the stress and strain noted within the spinal cord patients' age and sex. It was noted that the stress in each segment and axis was positively correlated with the degree of spine injury severity (AOSpine and Moore's) (R Spearman 0.39-0.64).

Similarly, the deformation in each zone and axis was posi- tively and significantly correlated with the degree of spine injury severity (R Spearman 0.40-0.62). The highest values of the correlation coefficient between the deformation and severity of the spinal injury was noted in segment 7 with a deformation in the lateral axis $(r=0.61)$. The highest coefficient of correlation between the deformation and injury degree according to the Moore's scale was noted in segment 6 with a deformation in the cephalo-caudal $(\mathrm{R}$ Spearman $=$ 0.62) (see Table 3).

Table 2. Summary of basic data describing the studied patient population and results of the Finite Element Method simulations. Median (with interquartile range in parenthesis) values reported.

\begin{tabular}{|c|c|c|c|c|c|c|c|c|c|c|c|}
\hline & \multirow{2}{*}{ Age } & \multirow{2}{*}{$\begin{array}{l}\text { Sex } \\
(M / F)\end{array}$} & \multirow{2}{*}{ Level } & \multirow{2}{*}{ AO } & \multirow{2}{*}{ Moore } & \multicolumn{3}{|c|}{ Stress [kPa] } & \multicolumn{3}{|c|}{ Strain } \\
\hline & & & & & & $\mathbf{X}$ & $\mathbf{Y}$ & $\mathbf{Z}$ & $\mathbf{X}$ & $\mathbf{Y}$ & $\mathbf{Z}$ \\
\hline Control group $(n=14)$ & $28(15)$ & $12 / 2$ & C5 & B1 & $5(5)$ & $\begin{array}{l}0.25 \\
(1.75)\end{array}$ & $\begin{array}{l}0 \\
(0.73)\end{array}$ & $\begin{array}{l}0.065 \\
(1.15)\end{array}$ & $\begin{array}{l}0 \\
(0.01)\end{array}$ & $\begin{array}{l}0 \\
(0.01)\end{array}$ & $\begin{array}{l}0 \\
(0.00)\end{array}$ \\
\hline Study group $(n=14)$ & $31(26)$ & $13 / 1$ & C5 & B2 & $10(7)$ & $\begin{array}{l}22.99 \\
(23.25)\end{array}$ & $\begin{array}{l}34.71 \\
(89.25)\end{array}$ & $\begin{array}{l}13.65 \\
(6.63)\end{array}$ & $\begin{array}{l}0.12 \\
(0.09)\end{array}$ & $\begin{array}{l}0.22 \\
(0.28)\end{array}$ & $\begin{array}{l}0.05 \\
(0.03)\end{array}$ \\
\hline
\end{tabular}

Note. AO - AOSpine classification ${ }^{[23]}$; Moore - scores according to Moore’s scale ${ }^{[25]}$; X - horizontal axis; $\mathrm{Y}$ - sagittal axis; $\mathrm{Z}$ - longitudinal axis

Table 3. Spearman's correlations between the stress and strain concentration noted in particular segments of the spinal cord (name in parentheses) and corresponding neurological deficits

\begin{tabular}{|c|c|c|c|c|c|c|}
\hline \multirow{2}{*}{ Item } & \multicolumn{3}{|c|}{ Stress } & \multicolumn{3}{|c|}{ Strain } \\
\hline & $\mathbf{X}$ & $\mathbf{Y}$ & $\mathbf{Z}$ & $\mathbf{X}$ & $\mathbf{Y}$ & $\mathbf{Z}$ \\
\hline Segmental movements (anterior horns of grey matter) & -0.49 & -0.57 & -0.55 & -0.56 & -0.54 & -0.61 \\
\hline Light-touch (anterior spinothalamic) & -0.75 & -0.44 & -0.63 & -0.70 & -0.65 & -0.62 \\
\hline Pain (lateral spinothalamic) & -0.64 & -0.59 & -0.62 & -0.68 & -0.68 & -0.50 \\
\hline Deep sensation (dorsal columns) & -0.43 & n.s. & n.s. & n.s. & n.s. & n.s. \\
\hline
\end{tabular}

Note. X - horizontal, Y - sagittal, Z - longitudinal directions

Factors differentiating between SG and CG were estimated based on the multiple regression model. The values in longitudinal axis (z), for both - stress (OR-6.3; 95\%CI 3.94-8.78; $p<.033$ ) and strain (OR -7.8; 95\%CI 3.03-10.19; $p<.046$ ) were found to play predictive roles in the appraisal of the neurological deficits risk after cervical SCI (see Table 4).

Table 4. Multiple logistic regression model presenting the risk of neurological deficits after traumatic cervical spinal cord injury

\begin{tabular}{|c|c|c|c|c|c|}
\hline \multicolumn{2}{|c|}{ Risk Factor } & \multirow{2}{*}{$\begin{array}{l}\text { Coefficient } \\
-178.6\end{array}$} & \multirow{2}{*}{$\begin{array}{l}\text { Odds Ratio } \\
3.8\end{array}$} & \multirow{2}{*}{$\begin{array}{l}\mathbf{9 5 \%} \text { CI } \\
2.12-6.70\end{array}$} & \multirow{2}{*}{$\begin{array}{l}\boldsymbol{p} \text { Value } \\
.482\end{array}$} \\
\hline \multirow{3}{*}{ Stress } & $\mathrm{X}$ & & & & \\
\hline & $\mathrm{Y}$ & -171.0 & 2 & $1.15-3.55$ & .387 \\
\hline & $\mathrm{Z}$ & 801.0 & 6.3 & $3.94-8.78$ & .033 \\
\hline \multirow{3}{*}{ Strain } & $\mathrm{X}$ & 88.9 & 5.8 & $1.70-9.87$ & .272 \\
\hline & $\mathrm{Y}$ & 40.7 & 4.4 & $1.61-15.13$ & .362 \\
\hline & $\mathrm{Z}$ & 142.3 & 7.8 & $3.03-10.19$ & .046 \\
\hline
\end{tabular}

The cut off value for stress was $8.1 \mathrm{kPa}$ (sensitivity $-85.7 \%$; specificity $-78.6 \%$; AUC-0.819, $p<.001)$ and for strain
0.0117 (sensitivity $-92.9 \%$; specificity $-72.5 \%$; AUC-0.645, $p<.001$ ) (see Figure 2).

The predictors of SCI in ASIA scale were tested with the multinominal ordinal logit regression. It was found that results in the longitudinal axis (z), in both, stress and strain, significantly correspond with grading in ASIA scale (see Figure 3).

Based on the linear regression, one grade change in ASIA scale from A to E correlates with the decrease in $\mathrm{z}$-axis by $4.01 \mathrm{kPa}$ and 0.012 in stress and strain respectively.

\section{DisCUSSION}

Traumatic SCI in the cervical segment is a problem of special significance. The young age of patients and the neurological after-effects, practically excluding them from widely understood social and professional activities means that the results of spinal cord injury are very serious. ${ }^{[33]}$ Primary spinal cord injury taking place over first 48 hours after tSCI is related to the massive cell death due to a direct mechanical impulse followed by blood-spinal cord barrier injury. ${ }^{[5-7]}$ 

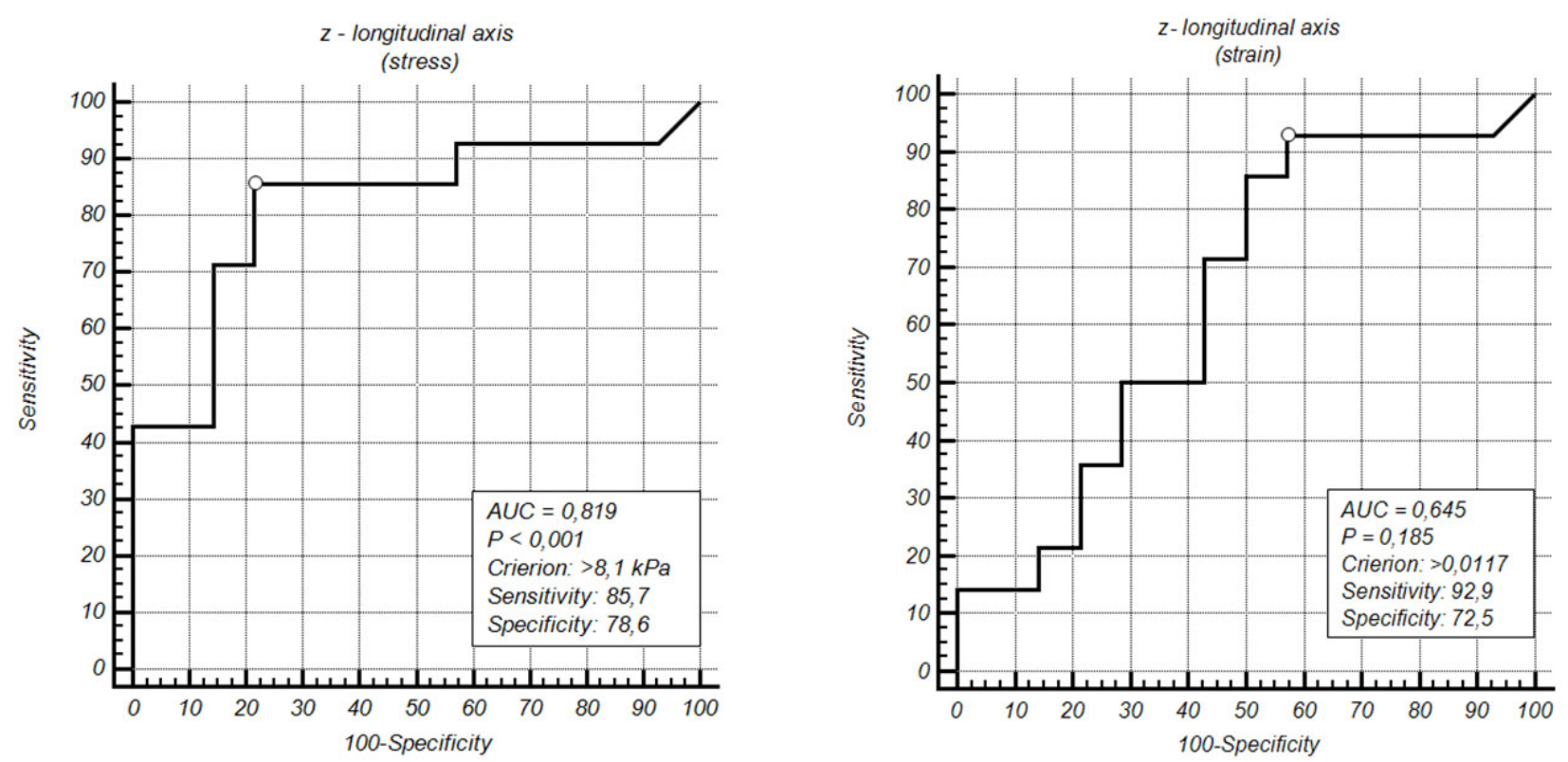

Figure 2. ROC curves for the results in longitudinal axes (z) in stress (left) and strain (right)
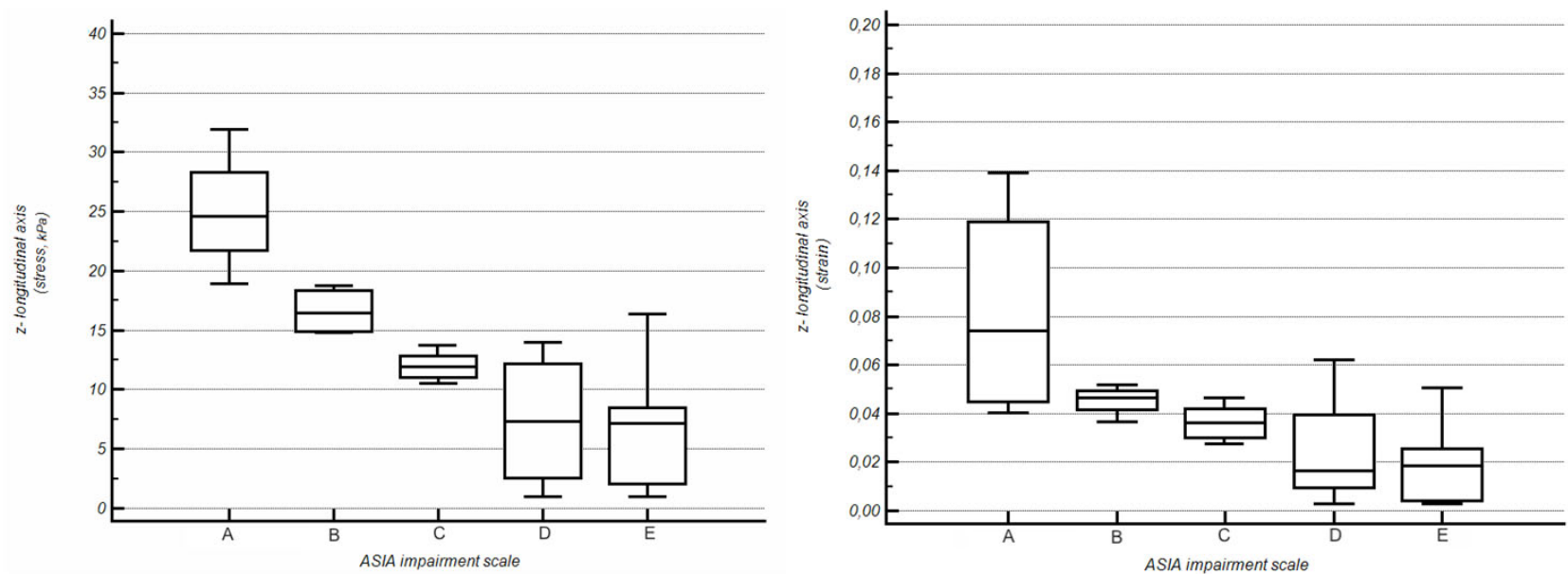

Figure 3. Relation between " $\mathrm{z}$ " (longitudinal) component of stress (left) and strain (right) and ASIA grade in the examined series of patients

The Box-and-whisker plots. The central box represents the values from the lower to upper quartile (25 to 75 percentile). The middle line represents the median. The vertical line extends from the minimum to the maximum value.

Sharma et al. ${ }^{[6]}$ published results of long-lasting observations of the function and role of blood-spinal cord barrier in the pathophysiology of primary and secondary SCI. Authors demonstrated that the impairment of the blood-spinal cord barrier occurring during the first seconds after an injury is a starting point for the process of the secondary injury. The inflammatory process reaction induces formation of swelling, haemorrhagic and necrotic foci, and also leads to the activation of apoptosis. Over weeks, months or even years following the primary injury gliosis, necrotic foci debridement, reconstitution of the blood-spinal cord barrier, formation of the glial scar, cysts and syrinxes can be observed. The extent and course of the secondary spinal cord injury are difficult to be predicted.

Maikos et al.$^{[7]}$ demonstrated that the range of blood-spinal cord barrier damage depends on the parameters of mechanical stimuli acting on the cord and the moment of injury. Moreover, in the experiment with FEM application they proved that the mechanical load induced by the injury correlates equally strongly with the size of the blood-spinal cord barrier damage. ${ }^{[5]}$ This constituted a principle for undertaking an attempt of FEM application in the analysis of clinical tSCI 
cases in humans.

In the present study we simulated 28 clinical cases of tSCI with the use of a validated 3D FEM model. The main limitation of our study was the fact that the injury moment simulation was based on presumptions and generalisations According to our knowledge, at present, it is not possible to truly reproduce the moment of impact, although a few efforts has been made in a past. ${ }^{[34,35]}$ FE models used in cited experiments were extremely complex, did not contain spinal cord and were applicable exclusively for the analyses of traffic-related injuries. We believe that our procedure - designed based on results of experimental studies - allowed to obtain results reflecting the reality at acceptable level. ${ }^{[1,3,4]}$ It was, indeed, initially confirmed in our previous publication revealing high correlation between stress and strain values and the severity of neurological deficits in tSCI patients. ${ }^{[18]}$

The FEM environment enabled observation of the model behaviour under controlled conditions. One should pay however attention to the fact that the loads applied to the spinal cord specimens were static. ${ }^{[18]}$ This enforced an application of a quasi-dynamic method of FEM analysis, which depends on immersing virtual osseous fractions in the spinal cord with indefinitely high speed. This methodology is accepted as an effective one and is used in many such cases. ${ }^{[16,17]}$

Another important limitation was the fact the model was not completed with virtual cervical vertebrae and cerebro-spinal fluid. At the current stage of research, lack of above mentioned structures in the model is sufficiently compensated by suitable fixation and deformation of the dura mater and modelling of the contact between it and the pia mater covering the spinal cord. As the mechanics of osseous and ligament structures of the spine plays a significant role during dynamic analyses, future studies on its full implementation for the model are fully justifiable. In the FEA analysis - despite of the recent remarkable progress on the IT - there is still a need to use simplified models and reasonable technological shortcuts. In all referred papers analysing spinal cord injuries authors used models representing only injured segment to decrease the number of Finite Elements, time of calculations and the possibility of errors. The ideal situation would be to assess the reaction of all of the human body to the impact but unfortunately - despite of constant attempts - it is still hardly possible due to the technological limitations.

The assessed group of patients was in many aspects a representative one. The age, sex distribution and injury mechanism of the group did not diverge from that presented in literature. ${ }^{[36,37]}$ Also, the types and mechanism of spinal injuries dominating in both subgroups - with and without neurological deficits - were consistent with the observations of other authors. ${ }^{[38,39]}$

According to our knowledge the presented study is the first which was performed on experimentally validated model, including real clinical cases into numerical simulation and analysis. Our observations are in general accordance with the study of Yan et al., ${ }^{[22]}$ who performed dynamic numerical simulation of burst fracture in thoracic spine and revealed similar values of strain to discovered by us in compressed cervical spinal cord. Moreover, authors confirmed strong correlation between the mechanical stress and strain concentration in injured spinal cord and the degree of the spinal canal occlusion. This observation also remains in consistent with our results, which was additionally confirmed by statistical analysis.

The results of the detailed analysis including above listed functional segments of the spinal cord are difficult for unequivocal interpretation. For example: the eighth segment was considered as the most susceptible to tension in the cephalo-caudal axis. An unambiguous demonstration of which segment is the most susceptible to damage leading to its dysfunction seems to be impossible at the present stage of study advancement. Small number of cases prevented us from carrying out the post-hoc analysis. It could allow us to predict the most vulnerable areas of the spinal cord section, which might be useful from both scientific and practical point of view and should be introduced on the basis of wider clinical material.

The results obtained allow to conclude that the application of the FEM enables simulation of the phenomenon of tSCI in particular clinical cases. The severity of damage of osseous and ligament structures of the spine, significantly influences the range of the mechanical effort of the damaged spinal cord which remains in accordance with the literature. ${ }^{[1,3,22]}$

The highest components of the state of stress and strain are observed in the anterior-posterior axis of the spinal cord. Neural tissue of the spinal cord is the most resistant to the mechanical stimulus acting in sagittal direction.

\section{Conclusion}

FEM simulation is useful model in the prediction of mechanical stress and strain in the cervical spinal after SCI. Severity of tSCI in ASIA scale positively correlates with the results of stress and longitudinal axis (z). Neural tissue of the spinal cord is the most resistant to the mechanical stimulus acting in sagittal direction. The current model is still considered greatly simplified compared to the clinical situations. Future efforts to include the surrounding bony elements are of great importance. 


\section{REFERENCES}

[1] Hall RM, Oakland RJ, Wilcox RK, et al. Spinal cord-fragment interactions following burst fracture: an in vitro model. J Neurosurg Spine. 2006 Sep; 5(3): 243-50. PMid: 16961086. http: //dx.doi.org/10.3171/spi.2006.5.3.243

[2] Swartz EE, Floyd RT, Cendoma M. Cervical spine functional anatomy and the biomechanics of injury due to compressive loading. J Athl Train. 2005 Sep; 40(3): 155-61. PMid: 16284634.

[3] Wilcox RK, Allen DJ, Hall RM, et al. A dynamic investigation of the burst fracture process using a combined experimental and finite element approach. Eur Spine J Off Publ Eur Spine Soc Eur Spinal Deform Soc Eur Sect Cerv Spine Res Soc. 2004 Oct; 13(6): 4818. PMid: 14714241. http://dx.doi.org/10.1007/s00586-0 03-0625-9

[4] Wilcox RK, Boerger TO, Allen DJ, et al. A dynamic study of thoracolumbar burst fractures. J Bone Joint Surg Am. 2003 Nov; 85-A(11): 2184-9. PMid: 14630851

[5] Maikos JT, Qian Z, Metaxas D, et al. Finite element analysis of spinal cord injury in the rat. J Neurotrauma. $2008 \mathrm{Jul}$; 25(7): 795-816. PMid: 18627257. http://dx.doi.org/10.1089/neu.2007.0423

[6] Sharma HS. Pathophysiology of blood-spinal cord barrier in traumatic injury and repair. Curr Pharm Des. 2005; 11(11): 1353-89. PMid: 15853669. http://dx.doi.org/10.2174/13816120535 07837

[7] Maikos JT, Shreiber DI. Immediate damage to the blood-spinal cord barrier due to mechanical trauma. J Neurotrauma. 2007 Mar; 24(3): 492-507. PMid: 17402855. http://dx.doi.org/10.1089/neu .2006 .0149

[8] Czyz M, Scigala K, Jarmundowicz W, et al. The biomechanical analysis of the traumatic cervical spinal cord injury using finite element approach. Acta Bioeng Biomech. 2008; 10(1): 43-54. PMid: 18634353.

[9] Panjabi M, White A. Biomechanics of nonacute cervical spinal cord trauma. Spine. 1988 Jul; 13(7): 838-42. PMid: 3057648. http://dx.doi.org/10.1097/00007632-198807000-00024

[10] Georgii J, Dick C. Efficient finite element methods for deformable bodies in medical applications. Crit Rev Biomed Eng. 2012; 40(2): 155-72. PMid: 22668240. http://dx.doi.org/10.1615/CritR evBiomedEng.v40.i2.50

[11] Gritsch K, Laroche N, Morgon L, et al. A systematic review of methods for tissue analysis in animal studies on orthodontic mini-implants. Orthod Craniofac Res. 2012 Aug; 15(3): 135-47. PMid: 22812436. http://dx.doi.org/10.1111/j.1601-6343.2012.01548.x

[12] Yoganandan N, Kumaresan S, Voo L, et al. Finite element applications in human cervical spine modeling. Spine. 1996 Aug 1; 21(15): 1824-34. PMid: 8855470. http://dx.doi.org/10.1097/00007 632-199608010-00022

[13] Podczeck F. Methods for the practical determination of the mechanical strength of tablets-from empiricism to science. Int J Pharm. 2012 Oct 15; 436(1-2): 214-32. PMid: 22776803. http://dx.doi.org /10.1016/j.ijpharm.2012.06.059

[14] Roy D, Kauffmann C, Delorme S, et al. A literature review of the numerical analysis of abdominal aortic aneurysms treated with endovascular stent grafts. Comput Math Methods Med. 2012; 2012: 820389. PMid: 22997538. http://dx.doi.org/10.1155/2012/820389

[15] Stops A, Wilcox R, Jin Z. Computational modelling of the natural hip: a review of finite element and multibody simulations. Comput Methods Biomech Biomed Engin. 2012; 15(9): 963-79. PMid: 21574077. http://dx.doi.org/10.1080/10255842.2011.567983

[16] Greaves CY, Gadala MS, Oxland TR. A three-dimensional finite element model of the cervical spine with spinal cord: an investigation of three injury mechanisms. Ann Biomed Eng. 2008 Mar; 36(3):
396-405. PMid: 18228144. http://dx.doi.org/10.1007/s10 439-008-9440-0

[17] Li XF, Dai LY. Three-dimensional finite element model of the cervical spinal cord: preliminary results of injury mechanism analysis. Spine. 2009 May 15; 34(11): 1140-7. PMid: 19444060. http://dx.doi.org/10.1097/BRS.0b013e31819e2af1

[18] Czyż M, Ścigała K, Będziński R, et al. Finite element modelling of the cervical spinal cord injury - clinical assessment. Acta Bioeng Biomech. 2012; 14(4): 23-9. PMid: 23394204.

[19] Ichihara K, Taguchi T, Shimada Y, et al. Gray matter of the bovine cervical spinal cord is mechanically more rigid and fragile than the white matter. J Neurotrauma. 2001 Mar; 18(3): 361-7. PMid: 11284555. http://dx.doi.org/10.1089/08977150151071053

[20] Ichihara K, Taguchi T, Sakuramoto I, et al. Mechanism of the spinal cord injury and the cervical spondylotic myelopathy: new approach based on the mechanical features of the spinal cord white and gray matter. J Neurosurg. 2003 Oct; 99(3 Suppl): 278-85. http://dx.doi.org/10.3171/spi.2003.99.3.0278

[21] Bertram CD, Bilston LE, Stoodley MA. Tensile radial stress in the spinal cord related to arachnoiditis or tethering: a numerical model. Med Biol Eng Comput. 2008 Jul; 46(7): 701-7. PMid: 18347831 http://dx.doi.org/10.1007/s11517-008-0332-0

[22] Yan YB, Qi W, Wu ZX, et al. Finite element study of the mechanical response in spinal cord during the thoracolumbar burst fracture. PloS One. 2012; 7(9): e41397. PMid: 23028426. http: //dx.doi.org/10.1371/journal.pone.0041397

[23] Anderson PA, Moore TA, Davis KW, et al. Cervical spine injury severity score. Assessment of reliability. J Bone Joint Surg Am. 2007 May; 89(5): 1057-65. PMid: 17473144. http://dx.doi.org/10. 2106/JBJS.F.00684

[24] Vaccaro AR, Hulbert RJ, Patel AA, et al. The subaxial cervical spine injury classification system: a novel approach to recognize the importance of morphology, neurology, and integrity of the disco-ligamentous complex. Spine. 2007 Oct 1; 32(21): 2365-74. PMid: 17906580. http://dx.doi.org/10.1097/BRS.0b013e3 $181557 \mathrm{~b} 92$

[25] Moore TA, Vaccaro AR, Anderson PA. Classification of lower cervical spine injuries. Spine. 2006 May 15; 31(11 Suppl): S37-43; discussion S61.

[26] Linassi G, Li P, Shan R, et al. A web-based computer program to determine the ASIA impairment classification. Spinal Cord. 2010 Feb; 48(2): 100-4. PMid: 19704413. http://dx.doi.org/10.10 $38 / \mathrm{sc} .2009 .98$

[27] Waring WP, Biering-Sorensen F, Burns S, et al. 2009 review and revisions of the international standards for the neurological classification of spinal cord injury. J Spinal Cord Med. 2010; 33(4): 346-52. PMid: 21061894. http://dx.doi.org/10.1080/10790268.20 10.11689712

[28] Czyż M, Scigała K, Jarmundowicz W, et al. Numerical model of the human cervical spinal cord-the development and validation. Acta Bioeng Biomech. 2011; 13(4): 51-8. PMid: 22339282.

[29] Tubbs RS, Salter G, Grabb PA, et al. The denticulate ligament: anatomy and functional significance. J Neurosurg. 2001 Apr; 94(2 Suppl): 271-5. http://dx.doi.org/10.3171/spi.2001.94.2 .0271

[30] Tunturi AR. Elasticity of the spinal cord, pia, and denticulate ligament in the dog. J Neurosurg. 1978 Jun; 48(6): 975-9. PMid: 660249. http://dx.doi.org/10.3171/jns.1978.48.6.0975

[31] Mazgajczyk E, Ścigała K, Czyż M, et al. Mechanical properties of cervical dura mater. Acta Bioeng Biomech Wroc Univ Technol. 2012; 14(1): 51-8. 
[32] Nicholas DS, Weller RO. The fine anatomy of the human spinal meninges. A light and scanning electron microscopy study. J Neurosurg. 1988 Aug; 69(2): 276-82. PMid: 3392571. http://dx.doi .org/10.3171/jns.1988.69.2.0276

[33] Rowland JW, Hawryluk GWJ, Kwon B, et al. Current status of acute spinal cord injury pathophysiology and emerging therapies: promise on the horizon. Neurosurg Focus. 2008; 25(5): E2. PMid: 18980476 http://dx.doi.org/10.3171/FOC. 2008.25.11.E2

[34] Sun J, Rojas A, Bertrand P, et al. Investigation of motorcyclist cervical spine trauma using HUMOS model. Traffic Inj Prev. 2012 Sep; 13(5): 519-28. PMid: 22931182. http://dx.doi.org/10.1080 /15389588.2012.656857

[35] Tropiano P, Thollon L, Arnoux PJ, et al. Using a finite element model to evaluate human injuries application to the HUMOS model in whiplash situation. Spine. 2004 Aug 15; 29(16): 1709-16.
PMid: 15303012. http://dx.doi.org/10.1097/01.BRS.0000 $135840.92373 .5 \mathrm{C}$

[36] O'Connor PJ. Trends in spinal cord injury. Accid Anal Prev. 2006 Jan; 38(1): 71-7. PMid: 16111641. http://dx.doi.org/10.10 $16 / j$. aap. 2005.03.025

[37] O'Connor PJ. Prevalence of spinal cord injury in Australia. Spinal Cord. 2005 Jan; 43(1): 42-6. PMid: 15326472. http://dx.doi.o $\mathrm{rg} / 10.1038 / \mathrm{sj} \cdot \mathrm{sc} .3101666$

[38] Carter JW, Mirza SK, Tencer AF, et al. Canal geometry changes associated with axial compressive cervical spine fracture. Spine. 2000 Jan; 25(1): 46-54. PMid: 10647160. http://dx.doi .org/10.10 97/00007632-200001010-00010

[39] Maiman DJ, Sances A, Myklebust JB, et al. Compression injuries of the cervical spine: a biomechanical analysis. Neurosurgery. 1983 Sep; 13(3): 254-60. PMid: 6621839. http://dx.doi.org/10.12 27/00006123-198309000-00007 